
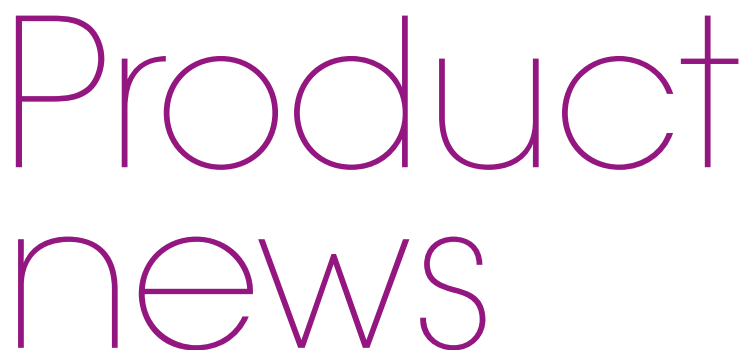

Product news is provided as a service to readers using text and images from

the manufacturer, supplier or distributor and does not imply endorsement by BDJ Team. Normal and prudent research should be exercised before purchase

\section{MINDSET IS THE KEY TO PRACTICE SUCCESS IN 2021}

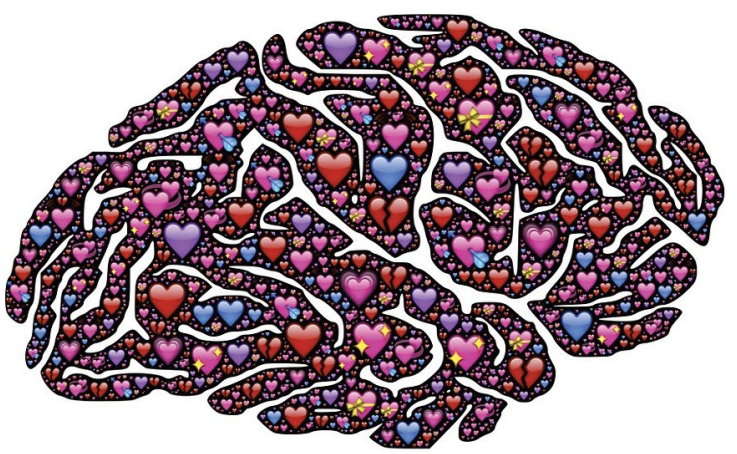

and might not even survive - fact.

Speaking about this unique chance, Tracy said, 'The reason training usually fails is because behaviour doesn't change, and new habits aren't developed. My unique approach to coaching focuses on the team learning to understand how their thoughts hold them back and where a new mindset is needed to make better choices'.

In a nutshell, the training

Tracy Stuart of NBS Training is offering dental teams the incredible opportunity to take part in a bespoke '12-month Profitable Dentist Plan', creating a bespoke blueprint formula for success.

Coming out of a challenging year, it is more important than ever before that dentists understand that changes are needed to their team's mindset. If things stay the same, practices will fail to thrive brings about a 'can do' attitude, resulting in practice owners who are amazed at how simple it can be to lead a team when you have Tracy on board.

To book a 30-minute strategy call with Tracy to see how she can help your practice achieve the same incredible results as previous clients, simply email tracy.stuart@ nbstraining.co.uk or call 01438217944.

\title{
DENTAL HANDPIECE EXPERTS AT YOUR SERVICE
}

Truly one of a kind, family-run Quintess Denta has decades of experience, expertise and excellence in handpiece repair and maintenance.

They are more than a repair or sales company; they are an integral part of your practice.

Quintess Denta guarantee high-quality services and competitive prices. Their restoration centre covers repairs to most popular handpiece brands, with expertise in fixing electric and air turbines as well as scalers.

Quintess Denta's technicians replace bearings, gears, $\mathrm{O}$-rings and seals, and have a reputation for being able to repair even the most demanding of devices to the highest standard.

Quintess Denta thinks that alongside supplying excellent products, their clients deserve a quick, reliable and efficient service delivered with a personal touch.

To find out more about Quintess Denta, contact Ian Creighton on +353 (0)1 691 8870, email ian@quintessdenta.com or visit quintessdenta.com

Alternatively, request your FREEPOST repair pack at quintessdenta.com/products/ freepost-repair-pack-new.

\section{FACILITATE OPTIMAL CLEANING}

TANDEX produces a range of brushes from the FLEXI interdental brush to UltraSoft options.

TANDEX is adding international standard (ISO) passage hole diameter (PHD) numbers to its packaging. ISO number defines a range of PHD spaces the brush can be squeezed into without deformation and PHD number defines the specific space the product can be squeezed into.

Inside, each product has a specific colour to make selection of the right size brush for every patient easy and to facilitate optimal cleaning.

TANDEX brushes are quality preventive tools that can help your patients avoid caries, why not try them?

For more information on Tandex's range of products, visit www.tandex.dk.

\section{NEW FREE CPD} FINDER SITE

Mydentalcpdfinder.co.uk is a new, free site which helps users find both free and paid-for CPD without having to laboriously search individual providers and websites.

Mydentalcpdfinder.co.uk solves two key problems for all dentists and dental team members: how to find free CPD all in one place and how to find subject-specific CPD specially to complete personal development plans (PDPs). Allocating the available CPD into subject categories Mydentalcpdfinder. co.uk also provides a summary of the content, amount of CPD and a link to the provider, improving choice and saving time in finding appropriate courses.

Mydentalcpdfinder.co.uk also gives the user the opportunity to sign up for free e-alerts when new CPD in specifically requested subject areas becomes available. Launched with over 150 CPD opportunities Mydentalcpdfinder.co.uk is a must: a one-stop site for seeking all your CPD needs.

https://mydentalcpdfinder.co.uk/ 